\title{
INTEGRAÇÃO CURRICULAR NO CURSO DE GRADUAÇÃO EM ENFERMAGEM
}

\section{Resumo}

O presente estudo discute algumas lições extraídas do processo de reformulação curricular, em que a integração constitui o desafio. São abordados as principais transformações e problemas decorrentes da concepção de educação integrada. Concluise que o confronto dos problemas cotidianos, o reconhecimento da diversidade dos sujeitos e o compartilhamento do poder são os principais desafios para a conquista de um currículo integrado.

Descritores: educação em enfermagem; ensino integrado em enfermagem; interdisciplinariedade

\begin{abstract}
This paper discusses a few lessons drawn from the curricular reform process, in which integration is a major challenge. The main transformations and problems arising from the concept of an ntegrated education system are approached. We have noticed that coping with daily problems, recognizing the existing diversity among individuals and power sharing are the main challenges to be conquered for the adoption of an integrated curriculum.

Descriptors: nursing education; integrated nursing education; interdisciplinary

Title: Curricular integration in nursing undergraduate programs
\end{abstract}

\begin{abstract}
Resumen
Este estudio discute algunas lecciones extraidas del proceso de reformulación curricular, en el cual la integración constituye el desafio. Se comentan las principales transformaciones y problemas que provienen del concepto deeducación integrada. Se concluye que la confrontación con los problemas cotidianos, el reconocimiento de la diversidad de los sujetos y el tener que compartir situaciones e instancias del poder son los principales desafíos para la conquista de un currículo integrado.

Descriptores: educación en enfermería; enseñanza integrada en enfermería; interdisciplinaridad

Título: Integración curricular en el curso de graduación en enfermería
\end{abstract}

\section{Introdução}

Vivemos hoje um processo de esgotamento do modelo tradicional de formação e de busca de caminhos que possam nos levar à educação crítica. São muitos os movimentos, processos de mudança e experiências em andamento, evitando-se a adoção de um modelo de formação.

Os conceitos fundamentais veiculados nesse processo de mudança são os de flexibilidade, integração e educação permanente, partindo do entendimento de que vivemos num tempo de comunicação em rede e de rápidas mudanças no conhecimento, o que exige mecanismos de educação condizentes com tais transformações.

Em termos de currículo, critica-se as grades fechadas de disciplinas com ênfase na transmissão de conteúdos. Propõe-se em contrapartida, diretrizes gerais, que abram às instituições de ensino a possibilidade de construírem propostas pedagógicas inovadoras, que respondam de forma articulada e democrática às necessidades sociais. E que seja capaz de contemplar a complexidade dos problemas da sociedade atual, o cenário de crise, as incertezas e as mudanças aceleradas do mundo moderno.

Considerando essa pretensão, é fundamental o desenvolvimento de uma visão sistêmica da formação, mediada por uma prática integradora, que busque aproximação e interação entre diferentes áreas de conhecimentos, projetos, atores e segmentos sociais.

O objetivo do presente estudo é refletir sobre o processo de mudança curricular a partir da abordagem da integração curricular no ensino de enfermagem.

\section{O Processo de Mudança Curricular na Enfermagem}

A formação do enfermeiro em nível de graduação tem sido amplamente debatida no cenário nacional e muitos problemas já foram identificados, estando sempre presentes nesses debates a necessidade imperiosa de revisar, atualizar e operar as disciplinas que compõem o currículo de graduação e a ausência de esquemas integralizadores e de linhas de ação compatíveis com a realidade de saúde do país.
Portanto, não é de hoje que críticas à organização curricular disciplinar são elaboradas, seja no campo da educação seja no campo da enfermagem. A despeito disso, o currículo disciplinar permanece sendo a organização dominante nos cursos de graduação.

A aquisição de um corpo de conhecimento formal, transmitido nas escolas, é um atributo-chave para identificação de um profissional. A educação serve de base para a maioria das ocupações nas sociedades modernas se firmar e constituir-se em áreas específicas de atuação no mercado de trabalho. Tornar-se útil, socialmente relevante e confiável perante os clientes, são elementos chave para o sucesso profissional de qualquer profissão que queira se firmar no mercado ${ }^{(1)}$.

$\mathrm{Na}$ década de 90, a enfermagem realizou uma discussão nacional em torno de uma proposta de novo currículo mínimo para o curso superior de enfermagem, naquele momento deposita-se no currículo expectativas de solução de problemas para além do que pode e deve ser um currículo.

A proposta de discussão em torno do currículo mínimo visava garantir um padrão mínimo de qualidade para todos os cursos de formação de enfermeiro. Já naquela época sinalizavase para a importância de se discutir políticas, princípios e diretrizes mais amplas para a formação do enfermeiro e reorientação da prática de enfermagem, no sentido de compreendê-la como parte de um processo coletivo e interdependente de trabalho e, essencial ao processo de atenção à saúde (2) .

As transformações operadas na vida social, no contexto internacional e nacional, desde então, impõem uma revisão da formação profissional do enfermeiro de modo a sintonizá-lo com a dinâmica dos novos tempos.

A enfermagem estabelece relações com outras práticas sociais, num processo de complementaridade, com o propósito de alcançar a integralidade do cuidado em saúde. O rápido desenvolvimento e incorporação de conhecimentos tem exigido uma compreensão cada vez mais profunda do contexto e dos processos de relações estratégicas que confluam para o alcance de metas comuns em diferentes níveis: local, regional

\footnotetext{
* Enfermeira. Mestra em Educação. Doutora em Enfermagem. Profa. Titular da Escola de Enfermagem Aurora de Afonso Costa, Universidade Federal Fluminense. Coordenadora do Núcleo de Estudos Imaginário, Criatividade e Cuidado em Saúde - NEICCS.

E-mail do autor:claumara@vr.microlink.com.br
} 
e mundial. Na perspectiva de utilização das potencialidades da enfermagem, os profissionais tem buscado alianças estratégicas e desenvolvido um trabalho integrado em rede, buscando fortalecer e ampliar seus conhecimentos e seu espaço de atuação(3) .

Hoje, a discussão é bem mais ampla, não se fala mais em termos de um currículo mínimo, onde há um grau de detalhamento de disciplinas e cargas horárias, mas de diretrizes curriculares e de Projeto Político-Pedagógico (PPP).

As novas Diretrizes Curriculares Nacionais para os Curso de Graduação em Enfermagem, recomendam a construção coletiva de um projeto político-pedagógico, centrado no aluno como sujeito da aprendizagem e apoiado no professor como facilitador e mediador do processo ensino-aprendizagem. Neste projeto deve-se buscar a formação integral e adequada do estudante através de uma articulação entre o ensino, a pesquisa e a extensão/assistência. Tendo a investigação como eixo integrador da formação acadêmica do enfermeiro, induzindo a implementação de programas de iniciação científica, propiciando ao aluno o desenvolvimento da sua criatividade e análise crítica $^{(4)}$

A idéia de PPP sugere os objetivos e diretrizes pedagógicas, políticas, teóricas, científicas e sociais de um curso. Dedicar-se à sua elaboração permite aclarar o sentido de que o Projeto Pedagógico tem implícita a visão de homem, de mundo e de um curso. Para isso tem-se que ter claro as diretrizes da instituição (sociais, políticas e econômicas) e seus objetivos no sentido de se verificar o que a universidade espera do cidadão que ela está formando(5)

Há grandes mudanças na sociedade moderna face ao contexto social, que apontam para a necessidade de buscarmos outras tecnologias, novas formas de gestão do trabalho e articulações político-sociais. Tais mudanças estão influenciando os próprios modelos e paradigmas científicos impondo inclusive uma nova visão de ciência ${ }^{(6)}$.

Frente às mudanças propostas, faz-se necessário ampliar as discussões com todos os atores envolvidos na formação do enfermeiro em cada instituição de Ensino Superior. As necessidades de treinamento e capacitação docente e o desenvolvimento de pesquisa que sustentem as novas práticas, são urgentes, já que a fundamentação teórico-metodológica e a prática docente em sala de aula ainda são fortemente influenciadas por abordagens tradicionais de ensinoaprendizagem e por uma relação assimétrica entre professoraluno.

É preciso considerar, que processos profundos de mudança na formação são complexos, envolvendo mudanças de conceitos, de postura, de lugares e de relações institucionais, levando ao enfrentamento de conhecimentos e valores cristalizados, hegemônicos, para construção de alternativas que não estão dadas. São processos que implicam conflitos, pressões e confrontações permanentes e que estão sob risco o tempo todo ${ }^{(7)}$

Com base nas orientações da LDB e das diretrizes curriculares recomendadas pelo SESU/MEC e pela ABEn, a organização curricular do Curso de Graduação em Enfermagem deverá pautar-se nos princípios da articulação entre ensino, pesquisa e extensão/assistência, garantindo um ensino crítico, reflexivo e criativo, que leve à construção do perfil almejado; atividades teóricas e práticas presentes desde o início do curso, permeando toda a formação do enfermeiro, de forma integrada e interdisciplinar; visão de educar para a cidadania e a participação plena na sociedade; princípios de autonomia institucional, de flexibilidade, integração estudo/trabalho e pluralidade no currículo; implementação de metodologia no processo ensinar-aprender que estimule o aluno a refletir sobre a realidade social e aprenda a aprender; definição de estratégias pedagógicas que articulem o saber, o saber fazer e o saber conviver, visando desenvolver o aprender a aprender, o aprender a ser, o aprender a fazer, o aprender a viver juntos e a aprender a conhecer que constituem atributos indispensáveis a formação do enfermeiro; estímulo às dinâmicas de trabalho em grupos, por favorecerem a discussão coletiva e as relações interpessoais; valorização das dimensões éticas e humanísticas, desenvolvendo no aluno e no enfermeiro atitudes e valores orientados para a cidadania e para a solidariedade; articulação da Graduação em Enfermagem com a licenciatura em Enfermagem; contribuição para a compreensão, interpretação, preservação, reforço, fomento e difusão das culturas nacionais e regionais, internacionais e históricas, em um contexto de pluralismo e diversidade cultural.

Pautando-se na concepção pedagógica crítico-social, o projeto pedagógico do curso de enfermagem tem como desafio fundamental a apropriação do conceito de integralidade pelos diferentes atores do curso, com vistas a desenvolver a capacidade de construir conhecimentos novos por meio de situações observadas na realidade, desencadeando um processo de ação-reflexão-ação e a construção de um currículo integrado. Os docentes precisam se empenhar na busca de novos modelos, novos olhares, novas abordagens. Adotando uma postura crítica de discussão e reflexão sobre os modelos pedagógicos atualmente utilizados ${ }^{(8)}$.

São necessárias alterações curriculares articuladas a um processo de sensibilização para o graduando quanto à valorização dos princípios humanos e de cidadania. Necessário se faz formar profissionais com capacidade técnica para influenciar nas decisões políticas e com sensibilidade poética para melhor compreender o self humano. A educação em enfermagem, além de garantir o conhecimento essencial a uma prática terapêutica, deverá promover as capacidades intelectuais e as competências para a investigação, avaliação crítica do exercício profissional e dos planos de ação política ${ }^{(9)}$.

Desta forma convém analisar as mudanças curriculares para que se possam perceber problemas e limitações, corrigir rumos, fazer novas proposições ou reafirmar definições pactuadas pelo coletivo do curso. É necessário estabelecer estratégias para sensibilizar e mobilizar todos os que precisam envolver-se na construção da mudança, levando-se em conta que são muitos os caminhos para que podem levar à educação crítica.

\section{Pedagogia da Interação e a Intedisciplinariedade}

Uma das questões fundamentais para a mudança da educação superior em nosso país é a incorporação efetiva, pelas universidades, dos conhecimentos disponíveis sobre a educação de adultos. Para adultos, o motor da aprendizagem é a superação de desafios, a resolução de problemas e, a construção do conhecimento novo que é feita tomando por base todos os conhecimentos e experiências prévias dos indivíduos ${ }^{(10)}$.

Sendo assim, o processo de educação de adultos e a formação universitária pressupõem a utilização de metodologias ativas de ensino-aprendizagem que proponham concretamente desafios a serem superados pelos estudantes, que Ihes possibilitem ocupar o lugar de sujeitos na construção dos conhecimentos e que coloquem o professor como facilitador e orientador desse processo. Ou seja, a educação de adultos e a formação universitária exigem uma pedagogia basicamente interativa ${ }^{(11)}$

Em muitas experiências de transformação do processo de formação profissional, a participação dos atores dos serviços e da comunidade na definição de conteúdos e na orientação dos trabalhos a serem desenvolvidos pelos estudantes tem sido essencial para que se revelem novos conteúdos e para que novas práticas (para responder aos novos problemas) sejam construídas. Novas práticas que incluem uma nova tecnologia no planejamento e construção de conteúdos e objetivos educacionais, agora não mais objetos exclusivos da prática acadêmica. 
Nesses espaços de práticas, vários projetos encontraram nas metodologias baseadas na concepção pedagógica crítico-reflexiva, especialmente a problematização, um instrumental adequado para articular a ação dos diferentes atores sobre os problemas da realidade. Um outro grupo de tecnologias utilizadas pelos projetos, especialmente na formação em medicina, são as metodologias de ensino baseado em problemas.

Nessa concepção pedagógica, é necessário adotar uma metodologia ativa, na qual o currículo é configurado de maneira integrada, para que se possam articular os vários conteúdos necessários a fim de dar conta de uma situação ou problema, independentemente da estrutura disciplinar. Trabalhar por problemas ou por problematização tem provocado a busca de caminhos que viabilizem abordagem interdisciplinar das questões. Trabalhar sobre problemas também tem aberto espaço para tratar de maneira mais integral temas e conteúdos, aumentando a chance de escapar das concepções reducionistas e, no caso da saúde, biologicistas ${ }^{(12)}$

A pedagogia da interação implica certo grau de democratização das relações dentro da universidade, já que está baseada numa relação entre sujeitos, em processos dinâmicos em que todos aprendem e que possibilitam o aperfeiçoamento contínuo de atitudes, conhecimentos e habilidades dos estudantes e também dos professores.

A evocação do trabalho interdisciplinar é antiga, contudo sua adoção é cada vez mais necessária no campo de atenção à saúde, tendo em vista a complexidade do processo de adoecer humano e a ampliação do campo de interdependência humana.

Interdisciplinaridade, portanto, é um conceito que se aplica às ciências, à produção do conhecimento e ao ensino. Se as pesquisas, para produzirem as respostas necessárias, têm que ser construídas interdisciplinarmente, o mesmo deve se aplicar ao processo de ensino-aprendizagem.

A possibilidade de uma compreensão integral do ser humano e do processo saúde-doença, objeto do trabalho em saúde, passa necessariamente por uma abordagem interdisciplinar, que implique demolição das fronteiras entre pesquisa e ensino-aprendizagem. E para tanto tem sido construídos currículos integrados baseados em módulos ou unidades que articulam problemas relevantes sob um recorte sistêmico ou de processos relevantes da vida e da morte.

\section{Integração e Reforma Curricular}

A organização dos currículos por disciplinas, apesar de ser amplamente aceito, desperta uma série de críticas vinculadas à idéia de que a divisão disciplinar do conhecimento é incapaz de dar conta da problemática social. Da preocupação com tal incapacidade surgiram diferentes mecanismos de contestação da idéia disciplinar, entre as quais destaca-se o modelo de currículo integrado.

O currículo integrado articula de forma dinâmica o ciclo básico e clínico, ensino, serviço e comunidade, prática e teoria, por meio da integração dos conteúdos, e abordagem de temas transversais como ética, criatividade, cidadania, interação e trabalho em equipe.

Para formarmos profissionais da saúde precisamos contemplar a educação, o intercâmbio, a cooperação, a pesquisa, o planejamento, o processo de decisão e a prestação de serviços, mas apesar disso, a formação profissional não se esgota em nenhum mecanismo integrador. Nem mesmo quando os agentes do processo educacional se encontram nos cenários comuns dos campos de prática do contexto universitário(13)

A interação precoce entre disciplinas do ciclo básico com o profissionalizante gera maior satisfação nos alunos, favorecendo o espírito crítico, a correlação da prática com a teoria e o compromisso do aluno com o processo de ensinoaprendizagem. A inovação das estratégias pedagógicas e a parceria entre docentes de diferentes disciplinas ajuda a supera o ensino tradicional(14)

No entanto, a organização tradicional da universidade tem a lógica das disciplinas e, as disciplinas isoladamente não dão conta de produzir as respostas necessárias a um mundo que é composto de uma multiplicidade de fatores, que não são mutuamente excludentes e sim explicados uns em relação aos outros. O mundo não é feito de coisas isoladas, existe uma complementaridade de dimensões. A compreensão desse mundo exige uma visão da realidade que transcenda os limites disciplinares.

O currículo integrado favorece as questões mais vitais e, por conseguinte, as questões conflituosas passam a ser enfrentadas, em virtude de sua característica interdisciplinar, justamente porque essas questões não estão confinadas nos limites de uma disciplina. Ele contribui para a criação de hábitos intelectuais que possibilitem levar em consideração as intervenções humanas de todas as perspectivas, facilitando a compreensão dos fenômenos, situações e processos, e, permite a visibilidade dos valores, ideologias e interesses presentes em todas as questões sociais e culturais. Também, favorece a partir do trabalho interdisciplinar, para que o(a)s professore(a)s sintam-se partícipes de uma equipe com metas comuns, de forma cooperativa ${ }^{(15)}$

Cada vez mais diferenciam-se e ampliam-se as áreas de saber. O fazer profissional demanda conhecimentos diversos que, sob distintas perspectivas, coexistem na busca de integrar o homem em suas várias dimensões como, por exemplo, biológica, política, social, filosófica, religiosa. A razão, a emoção, a quantidade, a qualidade, o técnico, o ético, o estético, o econômico, o político, o cultural e o científico convivem como saberes que se diferenciam, mas interrelacionam-se na tentativa de apontar caminhos que possibilitem a compreensão do homem e, sobretudo, o respeito a sua dignidade(16)

A despeito da crítica de que a divisão disciplinar do conhecimento é incapaz de dar conta da problemática social, a matriz disciplinar persiste como instrumento de organização e de controle, entretanto o fato de os currículos se organizarem em uma matriz disciplinar não impede que se criem diferentes mecanismos de integração, seja pela criação de disciplinas integradas, seja pela tentativa de articulação de disciplinas isoladas ${ }^{(17)}$

\section{Considerações Finais}

O confronto dos problemas cotidianos, o reconhecimento da diversidade dos sujeitos, o compartilhamento do poder são os principais desafios para a conquista de um currículo integrado. Para construir um projeto de fato inovador e condizente com as novas diretrizes curriculares é preciso avaliar o currículo, a cultura escolar, a história das disciplinas, as concepções existentes no interior da instituição e o processo de trabalho como um todo. Onde a mudança na organização curricular por meio de áreas interdisciplinares, temas transversais, áreas de projeto, assume posição central.

Apesar de valorizarem a integração curricular enquanto um aspecto muito importante da formação crítica do enfermeiro, alguns docentes consideram um risco desarticular o currículo disciplinar. Há uma preocupação concreta com a fragmentação do conteúdo e consequentemente com o próprio processo de trabalho docente, decorrente da crise no ensino superior, onde prevalece um sistema de avaliação baseado numa lógica produtivista, em que a quantidade de trabalho é estimulada em prejuízo da qualidade. Tal lógica, contrapõe-se aos princípios de um ensino crítico e integrador, levando o trabalho docente ao isolamento e a competitividade.

Construir um currículo integrado representa associar sentido ao saber; criatividade à razão, unir disciplinas e concepções diversas; reconhecer parcerias, interagir com diferentes culturas, ampliar continuamente as formas de participação. 


\section{Referências}

1. Machado MH. A profissão de enfermagem no século XXI. Revista Brasileira de Enfermagem, Brasília (DF) 1999 jul/ago;52(4):589-95.

2. Christófaro MA. Currículo mínimo para a formação do enfermeiro: na ordem do dia. Revista Brasileira de Enfermagem, Brasília (DF) 1991 abr/set;44 (2/3):7-9.

3. Sena RR, Brant MJC. Iniciativa de inovação do ensino de enfermagem na América Latina. Revista Brasileira de Enfermagem, Brasília (DF) 1999 mar/abr;52(2):243-50.

4. Ministério da Educação (BR). Diretrizes curriculares nacionais dos cursos de graduação em enfermagem, medicina e nutrição: parecer CNE/CES 1.133, de outubro de 2001. Brasília (DF); 2001.

5. Almeida A. O significado do projeto pedagógico. Boletim Educação, 1997;1(1)

6. Collet N, Schneider J, Corrêa A. A pesquisa em enfermagem: avanços e desafios. Revista Brasileira de Enfermagem, Brasília (DF) 2000 jan/fev;53(1):75-80.

7. Fauerwerker L. Mudanças na educação médica: os casos de Londrina e Marília. São Paulo: HUCITEC; 2002.

8. Chagas MIO, Barroso MGT, Varela ZMV. Vivenciando uma abordagem sócio-cultural no ensino de enfermagem. Revista Brasileira de Enfermagem, Brasília (DF) 2000 jan/fev;53(1):87-93.

9. Sá L. E a enfermagem no século XXI? Revista Brasileira de Enfermagem, Brasília (DF) 1999 maio/jun;52(3):375-84.
10. Freire P. Educação como prática de liberdade. Rio de Janeiro: Paz e Terra; 1976.

11. Bordenave J, Pereira A. Estratégias de ensino-aprendizagem. Rio de Janeiro: Vozes;1998.

12. Lück H. Pedagogia interdisciplinar; fundamentos teóricometodológicos. Petrópolis (RJ): Vozes; 1994.

13. Carvalho V. A formação profissional do enfermeiro. Caderno de Enfermagem, 1988 (1).

14. Utyama IKA, Macedo GGC, Janene SMA. Integração interdisciplinar no ensinar e aprender enfermagem: relato de uma experiência. Revista Brasileira de Enfermagem, Brasília (DF) 1999 jul/ ago;52(4):561-5.

15. Santomé JTA. Instituição escolar e a compreensão da realidade: o currículo integrado. In: Silva LH, organizador. Novos mapas culturais, novas perspectivas educacionais. Porto Alegre (RS): ARTMED; 1998.

16. Collet N, Schneider JF, Corrêa AK. A pesquisa em enfermagem: avanços e desafios. Revista Brasileira de Enfermagem, Brasília (DF) $2000 \mathrm{jan} / \mathrm{fev} ; 53(1): 75-80$.

17. Lopes $A$, Macedo $E$, organizadores. Disciplinas e integração curricular: história e políticas. Rio de Janeiro: DP\&A; 2002.

Data de Recebimento: 20/08/2003

Data de aprovação: 30/10/2003 